\title{
HUBUNGAN KINERJA OTAK DENGAN SPIRITUALITAS MANUSIA DIUKUR DENGAN MENGGUNAKAN INDONESIA SPIRITUAL HEALTH ASSESSMENT PADA PEGAWAI PEMDA KABUPATEN HALTENG PROVINSI MALUKU UTARA
}

\author{
${ }^{1}$ Juniarsih \\ ${ }^{2}$ Taufiq F. Pasiak \\ ${ }^{2}$ Sunny Wangko
}

\author{
${ }^{1}$ Kandidat Skripsi Fakultas Kedokteran Universitas Sam Ratulangi Manado \\ ${ }^{2}$ Bagian Anatomi-Histologi Fakultas Kedokteran Universitas Sam Ratulangi Manado \\ Email: juniarsih.uni@gmail.com
}

\begin{abstract}
Brain is the most complex part of human body. It regulates, monitors, and controls our actions and behaviors. By using SPECT, Amen observed the brain activity associated with soul and divided brain into 5 main systems: the prefrontal cortex, limbic system, basal ganglia, cingulatus gyrus (cingulate), and the temporal lobe. Spirituality is an empirical experience related to the presence of God in one's life with its manifestations in interpersonal and intrapersonal relationships. Spirituality has four dimensions, which are the meaning of life, spiritual experiences, positive emotions, and rituals. The spiritual measuring device used in Indonesia is Indonesia Spiritual Health Assessment (ISHA). This study aimed to determine the correlation between the human brain performance and spirituality measured with ISHA among employees (echelon II and III) in Halmahera Tengah, North Maluku province. This was a descriptive correlative study with a survey method. The Spearman's rank test showed an inversely correlation $(-0.005)$ with a sig. $0.968>\alpha=0.05$, which means that there is no correlation between the performance of human brain and spirituality, especially positive emotions and the limbic system. Conclusion: There was no correlation between the performance of the human brain and spirituality especially positive emotions and the limbic system.
\end{abstract}

Keywords: ISHA, brain, spirituality.

\begin{abstract}
Absrak: Otak merupakan bagian tubuh manusia yang sangat kompleks serta mengatur, mengawasi, dan mengendalikan tindakan dan perilaku tubuh. Dengan menggunakan SPECT, Amen mengamati aktivitas otak yang berhubungan dengan jiwa dan membagi otak dalam 5 sistem utama yaitu korteks prefrontalis, sistem limbik, ganglia basalis, Gyrus cingulatus (singulat), dan lobus temporalis. Spiritualitas adalah suatu pengalaman empirik berkaitan dengan kehadiran Tuhan dalam kehidupan seseorang dengan manifestasinya dalam hubungan interpersonal dan intrapersonal. Spiritualitas mempunyai 4 dimensi yaitu makna hidup, pengalaman spiritual, emosi positif, dan ritual. Di Indonesia alat ukur spiritual yang digunakan yaitu Indonesia Spiritual Health Assessment (ISHA). Penelitian ini bertujuan untuk mengetahui hubungan kinerja otak dengan spiritualitas manusia yang diukur menggunakan ISHA pada pegawai (pejabat essalon II dan III) Pemda Kabupaten Halmahera Tengah Provinsi Maluku Utara. Penelitian ini menggunakan metode deskriptif korelatif dan survei. Hasil uji korelasi Spearman menunjukkan korelasi terbalik $(-0,005)$ dengan sig 0,968 $>\boldsymbol{\alpha}=0,05$. Simpulan: Tidak terdapat hubungan antara kinerja otak dan spiritualitas khususnya emosi positif dan sistem limbik.
\end{abstract}

Kata kunci: ISHA, otak, spiritualitas 
Salah satu penelitian seorang ilmuwan neurosains Ramachandran mengungkapkan adanya The God Spot dalam otak manusia. Ramachandran mengungkapkan hal itu ketika meneliti aktivitas elektris pada salah satu bagian otak yang disebut Lobus temporalis yang menurutnya penting dalam pengalaman religius. Pola aktivitas elektris otak sangat berbeda-beda tergantung pada pengalaman setiap orang. Sebagai contoh, orang yang sedang menjelang meninggal dapat menghasilkan pola aktivitas elektris berbeda dengan orang yang sedang meditasi. Para ilmuwan kini percaya bahwa sejumlah struktur dalam otak memerlukan kerjasama untuk membantu kita mengalami spiritualitas. ${ }^{1}$

Francis Galton seorang penjelajah dan antropolog, beliau dapat dikatakan sebagai orang pertama yang mencoba meneliti secara statistik dan sistematik beberapa hal tentang yang berkaitan dengan agama. Galton merancang sejumlah kuesioner dan buat skala pengukuran dalam psikologi agama. Alat-alat ukur yang sudah pernah dibuat Galton dapat dikelompokkan ke dalam empat kelompok, ada yang diarahkan secara langsung mengukur spiritualitas dan agama, ada juga yang merupakan salah satu bagian saja dari alat ukur yang ditujukan untuk hal lain: mengukur kualitas hidup, mengukur perilaku, mengukur religiositas, dan mengukur spiritualitas. Lahirnya sejumlah pemeriksaan itu bukannya tanpa masalah. Persoalan validitas (apakah ukuran itu mengukur apa yang hendak diukur) dan reliabilitas (apakah hasilnya akan sama jika diukur pada orang yang sama, tapi waktu yang berbeda) juga menjadi masalah utama. $^{2}$

Di Indonesia, Universitas Islam Negeri (UIN) Sunan Kalijaga Yogyakarta mendirikan pusat studi yang diberi nama Center for Neuroscience Health and Spirituality (C-NET). ${ }^{3}$ C-NET merupakan lembaga resmi pertama di Indonesia yang meneliti dan mendokumentasikan secara ilmiah riset-riset hubungan spiritualitasreligiositas dengan kesehatan. ${ }^{2}$ Upaya pengembangan dan penelitian selama dua tahun terakhir memfokuskan pada riset mengenai otak, spiritualitas dan kesehatan. Hasil validasi yang dilakukan pada akhirnya telah berhasil menciptakan alat pemeriksaan kesehatan spiritual yang diberi nama Indonesia Spiritual Health Assessment (ISHA). ${ }^{3}$ ISHA adalah penelitian (asesmen) yang dibuat berdasarkan konsep teoritis spiritualitas dan terdiri dari tiga komponen pemeriksaan: ${ }^{2}$

1. Spiritual Health Item: Terdiri dari 90 soal untuk memeriksa 24 indikator kesehatan spiritual. Pernyataan dalam bentuk simulasi imajinatif.

2. Brain System Assessment: Terdiri dari 27 soal untuk mengecek system otak yang dominan bekerja.

3. Neurobiofeedback: Alat pemeriksaan yang berfungsi supporting terhadap ISHA. Tidak berhubungan langsung dengan konsep spiritualitas di atas, tetapi memberikan dukungan berarti berkaitan dengan kondisi terperiksa.

Pengkajian spiritual yang dilakukan oleh C-NET dua tahun membawa pengertian bahwa kesehatan spiritual tidak jauh berbeda dengan kesehatan fisik. ${ }^{3}$

Kesehatan adalah keadaan sehat, baik secara fisik, mental, spiritual, maupun sosial yang memungkinkan setiap orang untuk hidup produktif secara sosial dan ekonomis. ${ }^{4}$ Spiritualitas adalah suatu pengalaman empirik berkaitan dengan kehadiran Tuhan dalam kehidupan seseorang dengan manifestasinya dalam hubungan interpersonal dan intrapersonal. Ada empat dimensi yang digabungkan menjadi satu yaitu makna hidup, pengalaman spiritual, emosi positif dan ritual, maka inilah yang akan melahirkan spiritualitas. ${ }^{2,5}$

Sehubung dengan hal yang diuraikan diatas, maka menjadi sangat menarik bagi penulis untuk mengadakan penelitian khususnya mengetahui hubungan antara kinerja otak dengan spiritualitas manusia diukur menggunakan Indonesia Spiritual Health Assessment (ISHA) pada pegawai (pejabat essalon II dan III) Pemda Kabupaten Halteng Provinsi Maluku Utara. 


\section{METODE PENELITIAN}

Jenis penelitian ini deskriptif korelatif dengan metode survei. Tempat penelitian di Halmahera Tengah Provinsi Maluku Utara dan waktu penelitian mulai dari tanggal 19 -26 November 2012. Populasi yaitu pegawai (pejabat essalon II dan III) Pemda Halteng Provinsi Maluku Utara, yang berjumlah 129 orang.

Pengambilan sampel dalam penelitian ini dengan menggunakan rumus $\mathrm{n}=\mathrm{N} / 1^{+}$ $\mathrm{N}\left(\mathrm{d}^{2}\right)$, keterangan: $\mathrm{n}=$ Besar sampel, $\mathrm{N}=$ Besar populasi dan $d=$ Tingkat kepercayaan/ ketepatan yang diinginkan. ${ }^{6}$ Perhitungan: $n=129 / 1+129 .(01)^{2}=56,33$ dibulatkan menjadi 56. Maka jumlah sampel yang diambil dalam penelitian ini sebanyak 56 orang.

Dalam penelitian ini variabel bebas yaitu Otak dan variabel terikat yaitu Spiritualitas. Definisi operasional pada penelitian yaitu: Otak: mengacu pada kinerja otak seseorang, yang dinilai dengan ISHA. Spiritualitas: mengacu pada kesehatan spiriualitas seseorang, yang dinilai dengan ISHA. ISHA (Indonesia Spiritual Health Assessment): pemeriksaan yang dibuat berdasarkan konsep teoritis spiritualitas dan neurosains. Pegawai Pemda Halteng Provinsi Maluku Utara: pejabat essalon II (Staf Ahli Bupati, Asisten Bupati, Kepala Dinas, Kepala Badan) dan pejabat essalon III (Kepala Kantor, Kepala Bagian, Sekretaris Dinas/ Badan, Kepala Bidang).

Teknik pengumpulan data dilakukan dengan cara membagikan kuesioner Indonesia Spiritual Health Assessment (ISHA) kepada responden. Hasil analisis data disajikan dalam bentuk tabel dan di narasikan. Analisis data menggunakan korelasi Spearman karena kedua variabel merupakan variabel kategorik (kualitatif) yang merupakan skala ordinal.

\section{HASIL PENELITIAN}

Gambaran Umum Tempat Penelitian

Kabupaten Halmahera Tengah merupakan salah satu kabupaten di provinsi Maluku Utara, Indonesia. Ibukota kabupaten ini terletak di Weda. Kabupaten ini memiliki luas wilayah $19.971 \mathrm{~km}^{2}$ dan berpenduduk sebanyak 145.234 jiwa (2000). ${ }^{7,8}$

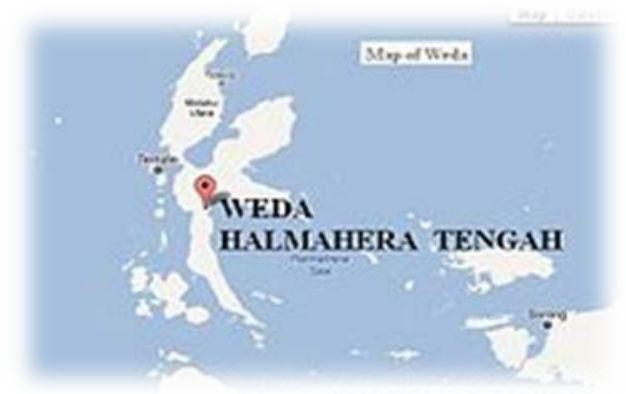

Gambar 1. Peta Weda, Halmahera Tengah Sumber:

http:/upload.wikimedia.org/wikipedia/id/thum b/f/fd/Weda_maluku.JPG/220px-

Weda_maluku.JPG

Karakteristik Responden

Responden yang ikut dalam penelitian ini yaitu pegawai pemda kabupaten halteng provinsi Maluku utara. Karakteristik responden dalam penelitian ini dapat dilihat pada Tabel 1.

Tabel 1. Distribusi frekuensi umur dan jenis kelamin responden

\begin{tabular}{c|c|c}
\multirow{2}{*}{$\begin{array}{c}\text { Rentang } \\
\text { Usia }\end{array}$} & \multicolumn{2}{|c}{ Jenis kelamin } \\
\cline { 2 - 3 } (Tahun) & $\begin{array}{c}\text { Laki-laki } \\
(\%)\end{array}$ & $\begin{array}{c}\text { Perempuan } \\
(\%)\end{array}$ \\
\hline $34-46$ & 40 & 50 \\
$47-58$ & 60 & 50 \\
Total & 100 & 100
\end{tabular}

Dari Tabel 1 dapat di lihat bahwa rentang usia responden yang ikut serta dalam penelitian ini yaitu antara 34-58 tahun. Persentase responden laki-laki yang berusia 34-46 tahun 40\% dan responden perempuan $50 \%$. Persentase responden laki-laki yang berusia 47-58 tahun 60\% dan responden perempuan 50\%. Secara keseluruhan yang berusia 34-46 tahun berjumlah 23 orang dan responden yang berusia 47-58 tahun berjumlah 33 orang.

Hasil Indonesia Spiritual Health Assesment yang dibagikan kepada responden dapat dilihat pada Tabel 2, serta Gambar 2 dan 3. Pengalaman spiritual pada responden laki-laki yang excellent 
berjumlah 10 orang; moderate 37 orang; dan improved 3 orang. Untuk pengalaman spiritual pada responden perempuan yaitu excellent 1 orang; moderate 4 orang; dan improved 1 orang.

Tabel 2. Hasil ISHA Spiritualitas

\begin{tabular}{cccccc}
\hline Jenis & Pengalaman & Emosi & Makna & \\
Kelamin & Interpretasi & Spiritual & Positif & Hidup & Ritual \\
\hline Laki-laki & Excellent & 10 & 44 & 46 & 30 \\
& Moderate & 37 & 6 & 4 & 19 \\
& Improved & 3 & 0 & 0 & 1 \\
\hline \multirow{2}{*}{ Perempuan } & Excellent & 1 & 5 & 6 & 4 \\
& Moderate & 4 & 1 & 0 & 2 \\
& Improved & 1 & 0 & 0 & 0 \\
\hline
\end{tabular}

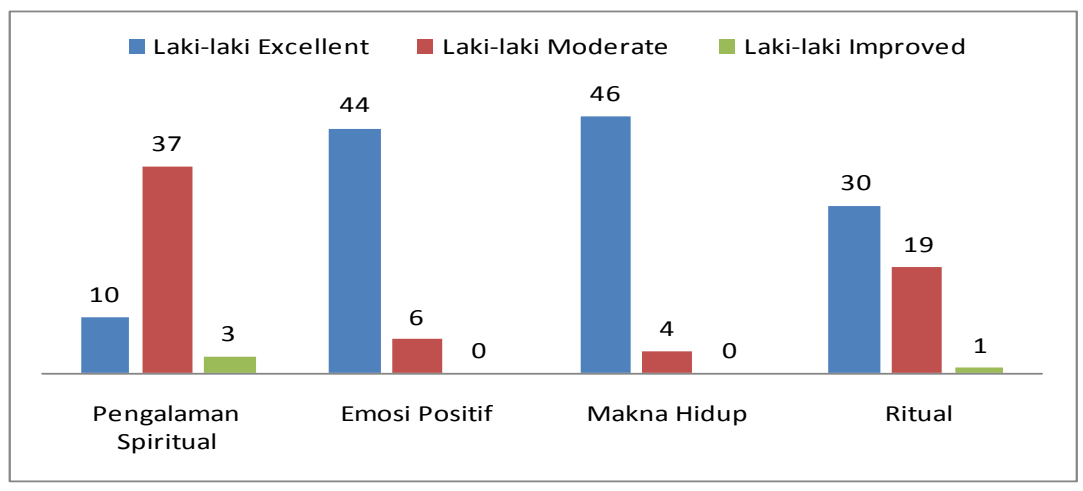

Gambar 2. Hasil ISHA Spiritualitas (Laki-laki)

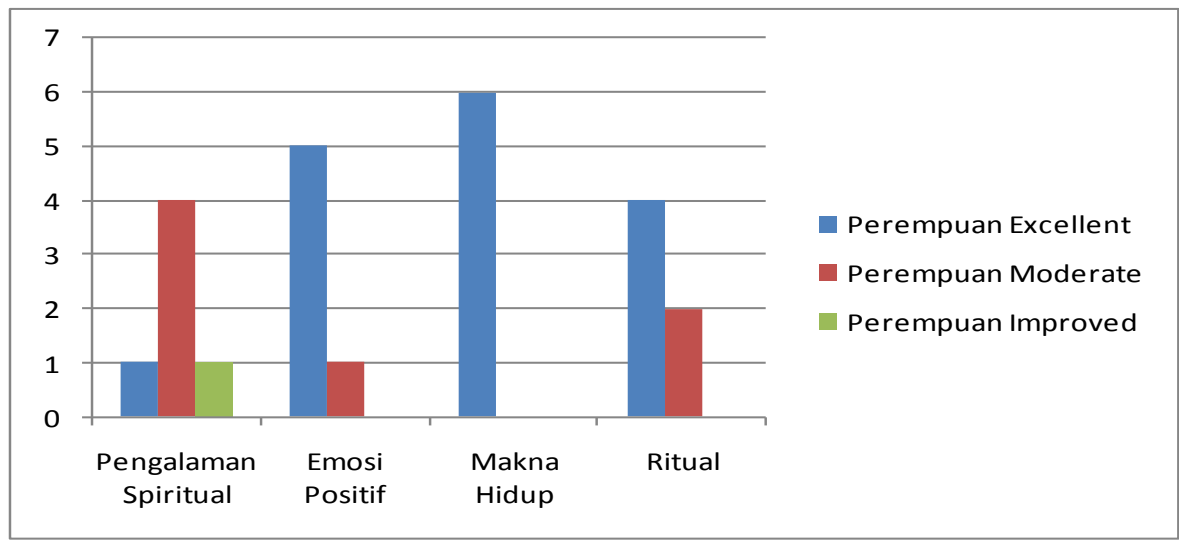

Gambar 3. Hasil ISHA Spiritualitas (Perempuan)

Emosi positif pada responden laki-laki yang excellent berjumlah 44 orang dan moderate 6 orang, sedangkan pada responden perempuan yang excellent 5 orang dan moderate 1 orang.
Makna hidup pada responden laki-laki yang excellent berjumlah 46 orang dan yang moderate berjumlah 4 orang, sedangkan pada responden perempuan didapatkan 6 orang yang excellent. 
Ritual pada responden laki-laki yang excellent berjumlah 30 orang, moderate berjumlah 19 orang dan sisanya improved 1 orang, sedangkan untuk ritual pada responden perempuan yaitu 4 orang excellent dan 2 orang moderate.

Berdasarkan Tabel 3, gambar 4 dan 5 dapat terlihat bahwa korteks prefrontalis pada responden laki-laki yang excellent berjumlah 34 orang dan 16 orang responden laki-laki yang moderate, sedangkan untuk nilai korteks prefrontalis pada responden perempuan yaitu 4 orang excellent dan 2 orang moderate.

Tabel 3. Hasil ISHA Dominasi Otak

\begin{tabular}{ccccccc}
\hline $\begin{array}{c}\text { Jenis } \\
\text { Kelamin }\end{array}$ & Interpretasi & $\begin{array}{c}\text { Korteks } \\
\text { Prefrontalis }\end{array}$ & $\begin{array}{c}\text { Sistem } \\
\text { Limbik }\end{array}$ & $\begin{array}{c}\text { Ganglia } \\
\text { Basalis }\end{array}$ & $\begin{array}{c}\text { Gyrus } \\
\text { Cingulatus }\end{array}$ & $\begin{array}{c}\text { Lobus } \\
\text { Temporalis }\end{array}$ \\
\hline Laki-laki & Excellent & 34 & 24 & 34 & 21 & 26 \\
& Moderate & 16 & 26 & 16 & 29 & 24 \\
& Improved & 0 & 0 & 0 & 0 & 0 \\
\hline Perempuan & Excellent & 4 & 2 & 3 & 2 & 1 \\
& Moderate & 2 & 4 & 3 & 3 & 5 \\
& Improved & 0 & 0 & 0 & 1 & 0 \\
\hline
\end{tabular}

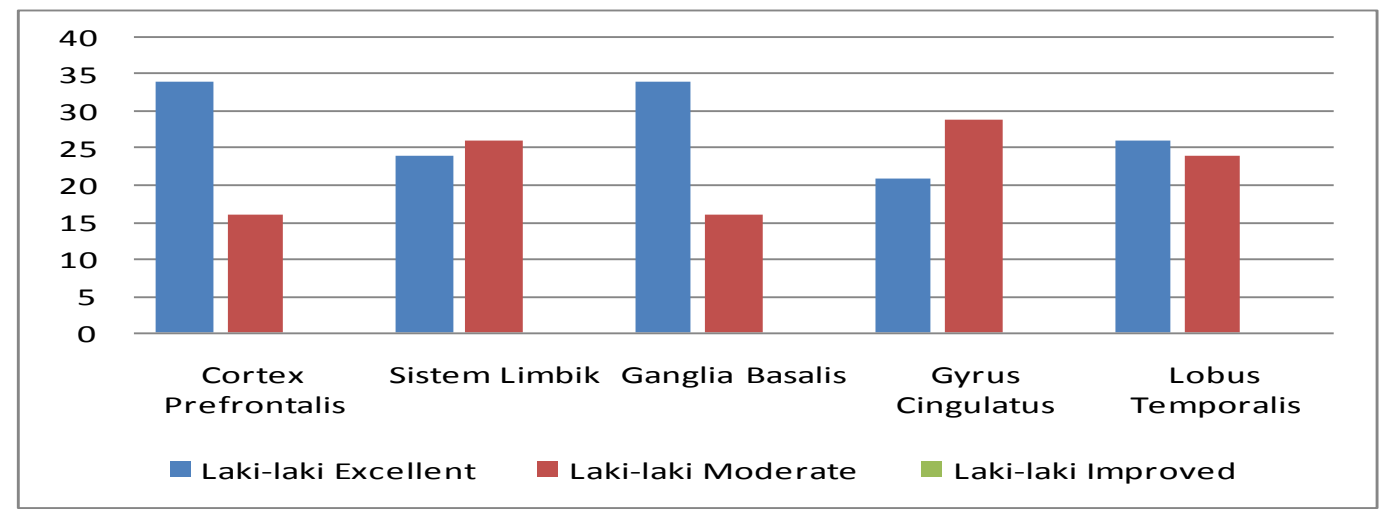

Gambar 4. Hasil ISHA Dominasi Otak (Laki-laki)

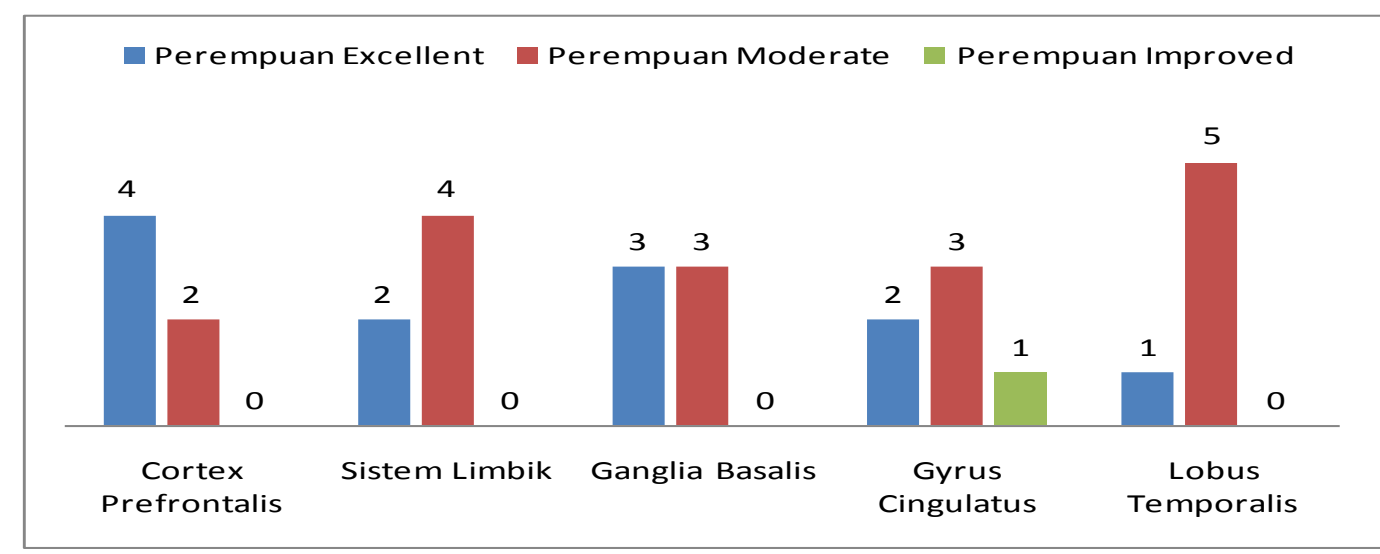

Gambar 5. Hasil ISHA Dominasi Otak (Perempuan)

Sistem limbik pada responden lakilaki yang excellent berjumlah 24 orang dan moderate 26 orang, sedangkan pada responden perempuan yaitu excellent 2 orang dan moderate 4 orang.

Ganglia basalis pada responden laki- 
laki yang excellent berjumlah 34 orang dan moderate 16 orang, pada responden perempuan yaitu excellent 3 orang dan moderate 3 orang.

Gyrus cingulatus pada responden lakilaki yang excellent berjumlah 21 orang dan moderate 29 orang, sedangkan pada responden perempuan excellent 2 orang, moderate 3 orang dan improved 1 orang.

Lobus temporalis pada responden laki-laki yang excellent berjumlah 26 orang dan moderate 24 orang, sedangkan pada responden perempuan yang excellent 1 orang dan yang moderate 5 orang.

\section{Hasil Analisis SPSS}

Tujuan utama dari penelitian ini untuk melihat hubungan kinerja otak dengan spiritualitas manusia yang diukur menggunakan ISHA pada pegawai Pemda Halteng Provinsi Maluku Utara. Untuk menghitung koefisien korelasi digunakan korelasi Spearman pada aplikasi SPSS statistics version 20.
Untuk melihat kebermaknaan hubungan antara dua variabel dapat dilihat pada signifikansi atau taraf kemaknaan yang ditentukan dengan nilai sig $<\alpha$. Taraf kemaknaan yang digunakan 0,05. Untuk kriteria koefisien korelasi atau nilai r yaitu berada antara -1 dan +1 , yang artinya jika nilai $r$ semakin mendekati +1 berarti menunjukkan hubungan positif yang kuat yaitu apabila nilai variabel $\mathrm{x}$ naik maka nilai variabel $b$ juga naik. Sedangkan, jika nilai r semakin mendekati -1 mengindikasikan hubungan negatif yang kuat yaitu apabila nilai variabel $\mathrm{x}$ naik maka nilai variabel y akan turun.,

Pada Tabel 4 dapat dilihat hasil perhitungan korelasi pada SPSS antara kinerja otak dan spiritualitas dalam hal ini bagian sistem limbik dan emosi positif yang berkorelasi terbalik $(-0,005)$ dan didapatkan sig $0,968>\boldsymbol{\alpha}=0,05$, berarti tidak terdapat hubungan antara emosi positif dan sistem limbik.

Tabel 4. Output korelasi sitem limbik dan emosi positif

Correlations

\begin{tabular}{|lll|r|r|}
\hline & & Emosi_Positif & \multicolumn{1}{|c|}{$\begin{array}{c}\text { Sistem } \\
\text { Limbik }\end{array}$} \\
\hline Spearman's rho & Emosi_Positif & Correlation Coefficient & 1.000 & -.005 \\
& & Sig. (2-tailed) & .968 \\
& $N$ & 56 & 56 \\
\cline { 2 - 5 } & Sistem_Limbik & Correlation Coefficient & -.005 & 1.000 \\
& Sig. (2-tailed) & .968 & \\
& $N$ & 56 & 56 \\
\hline
\end{tabular}

\section{BAHASAN}

Hasil analisis yang didapatkan menunjukkan tidak adanya hubungan antara sistem limbik dan emosi positif yang diukur dengan menggunakan ISHA. Hasil sebelumnya memperlihatkan lebih banyak nilai excellent pada responden laki-laki karena jumlah responden laki-laki lebih banyak dari perempuan.

Sistem limbik merupakan tempat pengalaman-pengalaman hidup yang diberikan warna emosi. Sistem limbik tersusun dari sejumlah subsistem yang saling bertautan dan saling memengaruhi dan secara bersama-sama melakukan fungsinya yaitu: ${ }^{11,12}$

1. Menyatukan informasi yang dicium (olfaktorius), dari organ internal (viseral) dan otot rangka (somatik) untuk mencapai kulit otak.

2. Mengontrol aktivitas yang diperlukan untuk pertahanan hidup, seperti makan dan minum.

3. Mengontrol aktivitas untuk memper- 
tahankan kelestarian spesis, seperti seks.

4. Mengatur perilaku emosi.

5. Penyimpanan memori emosi.

Sistem limbik

Sistem limbik terutama subsistem amygdala dam hippocampus merupakan objek kajian yang sedang berkembang pesat. Amygdala berperan penting dalam kecakapan emosi (emotional skill). Informasi yang di-relay talamus ditujukan ke kulit otak, tetapi karena hal tertentu informasi ini justru dibajak oleh amygdala (hijacking amygdala). Akibatnya, nalar dan pikiran tidak berjalan sebagaimana mestinya diganti dengan tanggapan bernada emosional. Pada tahun 1913, Kluver dan Bucy melaporkan bahwa pengangkatan seluruh otak bagian samping (lobus temporalis), termasuk pengangkatan amygdala dan hippocampus, dapat mengakibatkan perubahan perilaku pada monyet. Perilaku agresif menjadi hilang, makan dengan rakus dan tidak pandang bulu (apa saja dilahap), melakukan hubungan seks tidak pandang bulu (apa saja ditunggangi) dan cenderung menyukai sesama jantan. Banteng aduan yang sebelumnya galak dan agresif, setelah dirusak amygdala nya, menjadi lebih tenang dan tidak lagi galak. $^{11,12}$

Emosi positif merupakan emosi yang menyenangkan dan diinginkan oleh setiap orang. Menurut Al-Qur'an, kesenangan bukanlah satu-satunya harapan tertinggi manusia, tetapi juga ketakutan yang menyenangkan, seperti emosi taqwa kepada Allah. Takut dalam pengertian ini bukanlah takut cemas (anxiety), tetapi takut yang dapat memelihara (wiqâyah) manusia dari semua tindakan yang tak patut. Dalam hal ini, Al-Qur'an tak hentihentinya memotivasi manusia agar memperoleh dan mengembangkan emosi positif. $^{13,14}$ Emosi positif dibagi menjadi tiga jenis, yaitu: ${ }^{15}$

1. Emosi positif masa lalu berupa puas, bangga, dan tenang.

2. Emosi positif masa depan berupa optimis, harapan, percaya diri, kepercayaan, dan keyakinan.

3. Emosi positif masa sekarang dibagi dua yaitu kenikmatan dan gratifikasi. Kenikmatan terdiri atas kenikmatan lahiriah dan batiniah. Kenikmatan lahiriah merupakan emosi positif yang bersifat sementara dan berasal dari indra. Kenikmatan yang lebih tinggi (kenikmatan batiniah) didefinisikan dengan memerhatikan perasaan yang ditimbulkan seperti: semangat, rasa senang, riang, ceria, gembira, santai, dan lain-lain.

\section{SIMPULAN}

Dari hasil penelitian yang dilakukan pada pegawai Pemda Halteng Provinsi Maluku Utara dapat disimpulkan bahwa tidak terdapat hubungan antara kinerja otak dan spiritualitas khususnya antara sistem limbik dengan emosi positif.

\section{DAFTAR PUSTAKA}

1. Elzaky J. Buku Induk Mukjizat Kesehatan Ibadah. Jakarta: Zaman, 2011.

2. Pasiak T. Tuhan dalam Otak Manusia. Bandung: Mizan, 2012.

3. Deva M. UIN Sunan Kalijaga Buka Fakultas Kedokteran- Integrasikan Kesehatan Spiritual [cited 2012 Oct 17]. Available from: http://www.seputarindonesia.com/edisicetak/content/view/ 464319/

4. Undang-undang Republik Indonesia No.36 Tentang Kesehatan, Bab I Pasal 1.

5. Pasiak T. Neurosains, Spiritualitas, dan Reliji. Surabaya: Pusat Penerbitan dan Percetakan Unair (AUP); 2012.

6. Notoatmodjo S. Metodologi Penelitian Kesehatan. Jakarta: PT. Rineka Cipta; 2005.

7. Anonim. Kabupaten Halmahera Tengah [cited 2013 Sep 17]. Available from: http://id.m.wikipedia.org/wiki/Kabupat en_Halmahera_Tengah

8. Anonim. Weda, Halmahera Tengah [cited 2012 Sep 17]. Available from: http://id.m.wikipedia.org/wiki/Kabupat en_Halmahera_Tengah

9. Sopiyudin MD. Statistik untuk Kedokteran dan Kesehatan. Jakarta: Salemba Medika, 2008. 
Juniarsih, Pasiak, Wangko: Hubungan kinerja otak dengan spiritualitas ...

10. Sarwono J. Buku Pintar IBM SPSS Statistic 20. Jakarta: Elex Media Komputindo, 2011.

11. Pasiak T. Unlimited Potency of the Brain. Bandung: Mizan Pustaka, 2009.

12. Gst ING. Peran Religi dan Spiritual pada Bipolar. Surabaya: Pusat Penerbitan dan Percetakan Unair (AUP), 2012.

13. Darwis MH. Emosi. Jakarta: Erlangga, 2006.

14. Lama D. Seni Hidup Bahagia. Jakarta: Gramedia Pustaka Utama, 2000.

15. Seligman M. E. P. Authentic Happiness. New York: Free Press, 2002. 